\title{
Improvement of lumbar bone mass after infliximab therapy in Crohn's disease patients
}

\author{
Marina Mauro MD, Vladimir Radovic MD, David Armstrong MD
}

M Mauro, V Radovic, D Armstrong. Improvement of lumbar bone mass after infliximab therapy in Crohn's disease patients. Can J Gastroenterol 2007;21(10):637-642.

BACKGROUND: Patients with Crohn's disease (CD) have a high risk of developing osteoporosis, but the mechanisms underlying bone mass loss are unclear. Elevated proinflammatory cytokines, such as tumour necrosis factor-alpha ( TNF $\alpha)$, have been implicated in the pathogenesis of bone resorption.

AIM: To assess whether suppression of TNF $\alpha$ with infliximab treatment has a beneficial effect on lumbar bone mass.

METHODS: Adult CD patients who had received infliximab treatment, and who underwent lumbar densitometric evaluation before and during treatment, were selected. Adult CD patients who had never received infliximab treatment were selected as controls. Information regarding age, sex, weight, duration of $\mathrm{CD}$, use of glucocorticoids and bisphosphonates, and signs of disease activity between both densitometric measurements were collected.

RESULTS: Data from 45 patients were analyzed. The control group $(n=30$, mean $[ \pm$ SD] $26.7 \pm 9$ years of age) had a significantly higher increase in body weight between both evaluations $(6.26 \% \pm 8 \%)$ than the infliximab group $(n=15,30.6 \pm 13$ years), which had an increase of $0.3 \% \pm 7.4 \%$. There was a strong correlation between the final weight and lumbar bone mineral content (BMC) in both groups. The infliximab group had a significant increase in lumbar bone area $(4.15 \% \pm 6.6 \%)$, BMC $(12.8 \% \pm 13.6 \%)$ and bone mineral density $(8.13 \% \pm 7.7 \%)$ between both evaluations (interval $22.6 \pm 11$ months) compared with the control group. The increase in BMC in patients who had received infliximab treatment was significant when compared with control patients who had received glucocorticoids $(n=8)$ or had evidence of disease activity $(\mathrm{n}=13)$.

CONCLUSION: Infliximab therapy improved lumbar bone mass independent of nutritional status. This finding suggests that TNF $\alpha$ plays a role in bone loss in CD.

Key Words: Bone mass; Crohn's disease; Infliximab; Osteopenia; Osteoporosis

\section{L'amélioration de la masse osseuse lombaire après une thérapie à l'infliximab chez des personnes atteintes de la maladie de Crohn}

\begin{abstract}
HISTORIQUE : Les personnes atteintes de la maladie de Crohn (MC) sont très vulnérables à l'ostéoporose, mais les mécanismes de perte de la masse osseuse sous-jacente ne sont pas clairs. Des cytokines proinflammatoires élevées, tels que le facteur de nécrose tumorale alpha $(\mathrm{FNT} \alpha)$, participent à la pathogenèse de la résorption osseuse.

OBJECTIF : Évaluer si la suppression du FNT $\alpha$ par traitement à l'infliximab a un effet bénéfique sur la masse osseuse lombaire.

MÉTHODOLOGIE : Les auteurs ont sélectionné des adultes atteints de la $\mathrm{MC}$ qui avaient reçu un traitement à l'infliximab et subi une évaluation lombaire par densitométrie avant et pendant leur traitement. Comme sujets témoins, ils ont sélectionné des adultes atteints de la MC qui n'avaient jamais été traités à l'infliximab. Ils ont colligé de l'information au sujet de l'âge, du sexe, du poids, de la durée de la MC, de l'utilisation de glucocorticoïdes et de bisphosphonates et de signes d'activité de la maladie entre les deux mesures de densitométrie.

RÉSULTATS : Les auteurs ont analysé les données de 45 patients. Le groupe témoin ( $n=30$, moyenne d'âge $[ \pm E ́ T]$ de $26,7 \pm 9$ ans) avait beaucoup pris de poids entre les deux évaluations $(6,26 \% \pm 8 \%)$ par rapport au groupe prenant de l'infliximab ( $\mathrm{n}=15,30,6 \pm 13$ ans), dont la prise de poids était de $0,3 \% \pm 7,4 \%$. On remarquait une forte corrélation entre le poids final et le contenu minéral osseux (CMO) lombaire dans les deux groupes. Le groupe sous infliximab présentait une augmentation importante de la zone osseuse lombaire $(4,15 \% \pm 6,6 \%)$, du CMO $(12,8 \% \pm 13,6 \%)$ et de la densité minérale osseuse $(8,13 \% \pm 7,7 \%)$ entre les deux évaluations (intervalle de 22,6 \pm 11 mois) par rapport au groupe témoin. L'augmentation du $\mathrm{CMO}$ chez les patients traités à l'infliximab était importante par rapport aux sujets témoins, qui avaient pris des glucocorticoïdes $(n=8)$ ou présentaient des signes probants d'indications de la maladie $(\mathrm{n}=13)$.

CONCLUSION : La thérapie à l'infliximab a amélioré la masse osseuse lombaire, indépendamment du statut nutritionnel. Cette observation laisse supposer que le FNT $\alpha$ joue un rôle dans la perte osseuse en cas de MC.
\end{abstract}

Patients with Crohn's disease $(\mathrm{CD})$ have a high risk of developing osteoporosis, characterized by reduced bone mineral density (BMD) and an increased propensity for fractures. Previous studies (1-5) have demonstrated that between $13 \%$ and $42 \%$ of patients with CD have low BMD levels.
Two recent epidemiological studies $(6,7)$ have suggested that patients with $C D$ are between 1.4 and 2.5 times more likely to fracture a bone than the normal population. The largest risk was observed at the spine, particularly in women, with a 6.5-fold increase in fracture risk (8).

Intestinal Disease Research Program Eु Division of Gastroenterology, McMaster University, Hamilton, Ontario

Correspondence: Dr David Armstrong, Associate Professor, Division of Gastroenterology, HSC-2F55, McMaster University Medical Centre, 1200 Main Street West, Hamilton, Ontario L8N 325. Telephone 905-521-2100 ext 76404, fax 905-523-6048,

e-mailarmstro@mcmaster.ca

Received for publication October 23, 2006. Accepted January 18, 2007 


\begin{tabular}{|c|c|c|c|}
\hline Characteristic & $\begin{array}{l}\text { nfliximab group, } \\
n=15\end{array}$ & $\begin{array}{c}\text { Control group, } \\
n=30\end{array}$ & $\mathbf{P}$ \\
\hline Age, years* & $30.6 \pm 13$ & $26.7 \pm 9$ & NS \\
\hline Sex (female:male), $\mathrm{n}$ & $9: 6$ & $22: 8$ & NS \\
\hline Age at diagnosis of CD, years* & $19.2 \pm 9.2$ & $18.3 \pm 8.5$ & NS \\
\hline Years of $C D^{*}$ & $11.2 \pm 6$ & $8.5 \pm 5.3$ & NS \\
\hline Final weight, $\mathrm{kg}^{*}$ & $70 \pm 18$ & $70.6 \pm 1$ & NS \\
\hline Weight change, \%* & $0.3 \pm 7.4$ & $6.26 \pm 8$ & $0.02^{\dagger}$ \\
\hline Bisphosphonates, \% & 20 & 17 & NS \\
\hline Glucocorticoids, \% & 46 & 26 & NS \\
\hline Flares or disease activity, $\mathrm{n}$ & 15 & 13 & NS \\
\hline
\end{tabular}

${ }^{*}$ Data are expressed as mean $\pm S D,{ }^{\dagger} P<0.05$. NS Not significant

Osteoporosis with osteoporotic pain syndromes and fragility fractures can significantly increase morbidity in affected patients and have a negative impact on quality of life.

The mechanisms underlying this lower BMD have not been clearly defined, but a number of factors have been implicated. The main pathophysiological factors under discussion include aging, sex, overall poor nutrition and the impaired absorption of nutrients that are essential for bone metabolism (vitamin D and calcium), glucocorticoid treatment, hypogonadism and the chronic inflammatory process, involving not only the bowel, but also the bone (9-14).

Circulating proinflammatory cytokines are elevated in CD patients with active inflammation and in patients with fistulizing $\mathrm{CD}$, and tumour necrosis factor-alpha ( $T N F \alpha$ ) plays a pivotal role by inducing a wide variety of inflammatory responses (15-17).

Active inflammation and elevated proinflammatory cytokines have been implicated in the pathogenesis of bone resorption $(18,19)$. TNF $\alpha$, interleukin-1-beta and interleukin-6, among others, potentially cause bone loss by both increasing bone resorption and inhibiting bone formation (14,20-23). Therefore, a modality that downregulates TNF $\alpha$ could potentially lead to improved BMD in patients with active CD. AntiTNF $\alpha$ chimeric antibody (infliximab) therapy is an effective treatment for induction of remission and prevention of relapse in patients with inflammatory bowel disease and perianal fistulizing CD (24,25).

Given the known in vitro effects of TNF $\alpha$ on osteoblasts and osteoclasts, the aim of the present study was to assess whether treatment with infliximab had a beneficial effect on lumbar bone mass.

\section{METHODS}

The study protocol was approved by the McMaster University Research Ethics Board (Hamilton, Ontario).

A retrospective chart review was performed to select adult CD patients who had received treatment with infliximab (Remicade [Schering-Plough Canada Inc, Canada]) for the first time, and who underwent a densitometric evaluation with dual-energy $\mathrm{x}$-ray absorptiometry before and during infliximab treatment. Only patients who had both densitometric assessments performed by the same dual-energy $\mathrm{x}$-ray absorptiometry instrument (Hologic Discovery A [Hologic Inc, USA]) were included. Patients received infliximab
( $5 \mathrm{mg} / \mathrm{kg}$ ) at intervals of four to eight weeks for a mean period of 18 months.

At Hamilton Health Sciences, McMaster University site (Hamilton, $\mathrm{ON}$ ), patients with CD usually undergo a densitometric evaluation at some point and a follow-up densitometry every two to three years.

Patients with CD who had not received treatment with infliximab and had two densitometric evaluations at least 12 months apart were selected as controls. Postmenopausal women and men older than 55 years of age were excluded.

All patients had small bowel disease with or without colonic involvement.

Laboratory data to assess bone metabolism at the time of the first densitometric evaluation were collected. Patients with low serum calcium, phosphorus or vitamin D levels, or with elevated serum levels of parathormone and/or alkaline phosphatase 20\% above the normal value $(120 \mathrm{U} / \mathrm{L})$ were excluded.

Densitometric evaluation included bone area, bone mineral content $(\mathrm{BMC})$ and $\mathrm{BMD}(\mathrm{BMD}=\mathrm{BMC} /$ projected area of the region scanned $\left[\mathrm{g} / \mathrm{cm}^{2}\right]$ ) in the lumbar area (L1 to L4) and both hips. BMD results were expressed in absolute values $\left(\mathrm{g} / \mathrm{cm}^{2}\right)$ and as the number of SDs from the peak bone mass of a young adult sex-matched reference population ( $\mathrm{T}$ score) and as the number of SDs from the mean of age- and sex-matched control patients ( $\mathrm{Z}$ score). Osteopenia was defined, based on the World Health Organization criteria, as a T score between -1 and -2.5 , and osteoporosis was defined as a $T$ score of less than -2.5 .

Sex, age, age at diagnosis and duration of CD were assessed. Information regarding weight, percentage of weight change, use of bisphosphonates, use of glucocorticoids, and the number of flares or signs of disease activity during the periods between both densitometric measurements was collected.

Results are expressed as the mean \pm SD. Baseline characteristics of the study population and control groups were analyzed using descriptive statistics. Temporal changes in densitometric results for individuals were calculated. Comparisons between groups were performed using the standard $t$ test for normally distributed values. Simple correlations were analyzed as required.

\section{RESULTS}

\section{Patients}

Data from 15 patients (six men and nine women) with CD $(30.6 \pm 13$ years old) who had received treatment with infliximab were analyzed. Thirty patients (eight men and 22 women) with CD (26.7 \pm 9 years old) who had never received treatment with infliximab were included in the control group. Table 1 shows the characteristics of both groups.

There was no significant difference between both groups with respect to age, sex distribution, age at diagnosis, disease duration and final weight. The control group had a significant increase in body weight between the two densitometric determinations compared with the infliximab group $(6.26 \% \pm 8 \%$ versus $0.3 \% \pm 7.4 \%$, respectively). In the period between the two densitometric evaluations, $20 \%$ of the patients in the infliximab group and $17 \%$ of the patients in the control group received bisphosphonates. Forty-six per cent of the patients in the infliximab group received a mean dose of $10 \pm 5 \mathrm{mg} /$ day of prednisone, and the dose was maintained between the densitometric determinations; $26 \%$ of the control group received a mean dose of $10 \pm 3 \mathrm{mg} /$ day of prednisone for a mean period of three months. 
TABLE 2

Comparison between the baseline and second lumbar densitometric evaluations in the infliximab and control groups

\begin{tabular}{|c|c|c|c|c|c|c|}
\hline \multirow[b]{2}{*}{ Measurement } & \multicolumn{3}{|c|}{ Infliximab group } & \multicolumn{3}{|c|}{ Control group } \\
\hline & Baseline evaluation & Second evaluation & $\%$ change & Baseline evaluation & Second evaluation & $\%$ change \\
\hline Bone area, $\mathrm{cm}^{2}$ & $56.7 \pm 9.4$ & $58.8 \pm 8.9$ & $4.15 \pm 6.6^{*}$ & $59 \pm 9.7$ & $56.9 \pm 9.4$ & $-1.35 \pm 7.3$ \\
\hline $\mathrm{BMC}, \mathrm{g}$ & $51.8 \pm 13.7$ & $57.1 \pm 10.4$ & $12.8 \pm 13.6^{*}$ & $57.0 \pm 14.0$ & $56.1 \pm 12.6$ & $0.29 \pm 8.6$ \\
\hline $\mathrm{BMD}, \mathrm{g} / \mathrm{cm}^{2}$ & $0.90 \pm 0.15$ & $0.97 \pm 0.12$ & $8.13 \pm 7.7^{*}$ & $0.97 \pm 0.12$ & $0.98 \pm 0.13$ & $1.55 \pm 4$ \\
\hline
\end{tabular}

Data are expressed as mean $\pm S D$. ${ }^{*} P<0.01$. BMC Bone mineral content; BMD Bone mineral density

Densitometric evaluation: Infliximab group versus control group

The baseline densitometric evaluation was performed $9 \pm 7$ months before the first infusion of infliximab.

Lumbar bone mass: In the first densitometric evaluation, osteopenia was found in $46 \%$ and osteoporosis was found in $20 \%$ of the patients in the infliximab group. Osteopenia was found in $26.6 \%$ and osteoporosis was found in $10 \%$ of the patients in the control group.

The first and second densitometric evaluations were $22.6 \pm 11$ months apart in the infliximab group and $20.4 \pm 8$ months apart in the control group.

In the second densitometric evaluation, osteopenia was found in $33 \%$ and osteoporosis in $6.6 \%$ of the patients in the infliximab group. Osteopenia was found in $26.6 \%$ and osteoporosis in $10 \%$ of the patients in the control group.

There were no significant differences in the lumbar bone area, BMC, BMD, and $\mathrm{T}$ and $\mathrm{Z}$ scores between both groups.

The infliximab group demonstrated significant increases in the lumbar bone area, BMC and BMD compared with the control group $(\mathrm{P}<0.01)$ (Table 2, Figures 1 and 2).

When only patients who had osteopenia or osteoporosis in the first densitometric determination were included in the analysis, the infliximab group still demonstrated significant increases in the lumbar bone area, BMC and BMD compared with the control group $(\mathrm{P}<0.01)$.

There was a strong correlation between the final weight and the second determination of lumbar BMC in the infliximab group $(\mathrm{r}=0.66 ; \mathrm{P}=0.004)$ and in the control group $(r=0.40 ; P=0.003)$.

Hip bone mass: Only nine patients in the infliximab group and 25 patients in the control group had densitometric evaluations of both hips.

In the first densitometric evaluation, four patients in the infliximab group and 12 patients in the control group had osteopenia. One patient in the infliximab group and two patients in the control group had osteoporosis. In the second densitometric evaluation, five patients had osteopenia in the infliximab group. Ten patients had osteopenia and one had osteoporosis in the control group.

There were no significant differences between both groups with respect to bone area, $\mathrm{BMC}, \mathrm{BMD}$, and $\mathrm{T}$ and $\mathrm{Z}$ scores in either hip.

The infliximab group demonstrated increases in BMC (3.7\% $\pm 6.5 \%$ in the left hip; $5.7 \% \pm 12.4 \%$ in the right hip) and $\operatorname{BMD}(2.7 \% \pm 6.0 \%$ in the left hip; $5.6 \% \pm 7.0 \%$ in the right hip) between both densitometric evaluations.

The control group demonstrated increases in BMC of $1.3 \% \pm 9.0 \%$ and in BMD of $1.3 \% \pm 4.5 \%$ in the left hip, and decreases in BMC of $-1.0 \% \pm 8.3 \%$ and in BMD of $-0.2 \% \pm 4.6 \%$ in the right hip) between both densitometric evaluations. In the infliximab group, the increase in BMD in

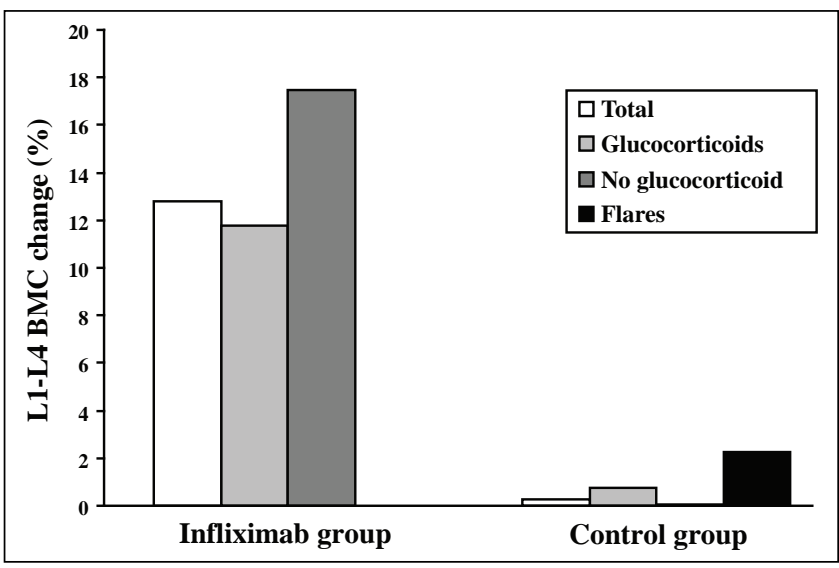

Figure 1) Percentage change in L1 to L4 bone mineral content (BMC) between baseline and second densitometric evaluations in the infliximab group (total, and subgroups with and without glucocorticoids) and control group (total, subgroups with and without glucocorticoids, and subgroup with history of flares)

the right hip was statistically significant compared with the control group.

Lumbar bone mass - infliximab group versus control subgroup receiving glucocorticoids: A subgroup of eight patients in the control group who received glucocorticoids between both densitometric determinations (four patients had osteopenia and one patient had osteoporosis) was compared with the infliximab group. This subgroup demonstrated a significant increase in body weight between both densitometric evaluations compared with the infliximab group $(10.6 \% \pm 7.3 \%$ versus $0.3 \% \pm 7.4 \%)$. There were no significant differences in the first or in the second lumbar BMD measurement, and $\mathrm{T}$ and $\mathrm{Z}$ scores between both groups. This subgroup had a $0.77 \%$ increase in the lumbar BMC. The infliximab group had a significant increase in lumbar BMC compared with this subgroup (12.8\% $\pm 13.6 \%$ versus $0.77 \% \pm 7 \%, P=0.029$ ) (Figure 1 ).

In the infliximab group, there was no significant difference in the percentage of BMC change between patients with $(n=7)$ and without $(n=8)$ glucocorticoid therapy $(11.8 \% \pm 14.8 \%$ versus $17.5 \% \pm 13.5 \%)$.

Lumbar bone mass - infliximab group versus control subgroup with active disease: A subgroup of 13 patients in the control group who had flares or signs of disease activity between both densitometric determinations (this group included the eight patients who received glucocorticoids) was compared with the infliximab group. Four patients in this subgroup had lumbar osteopenia and two had lumbar osteoporosis in both the first and second densitometric evaluations. The control group demonstrated an increase of $6.8 \% \pm 9.0 \%$ in body weight between both densitometric evaluations. There were no significant differences 


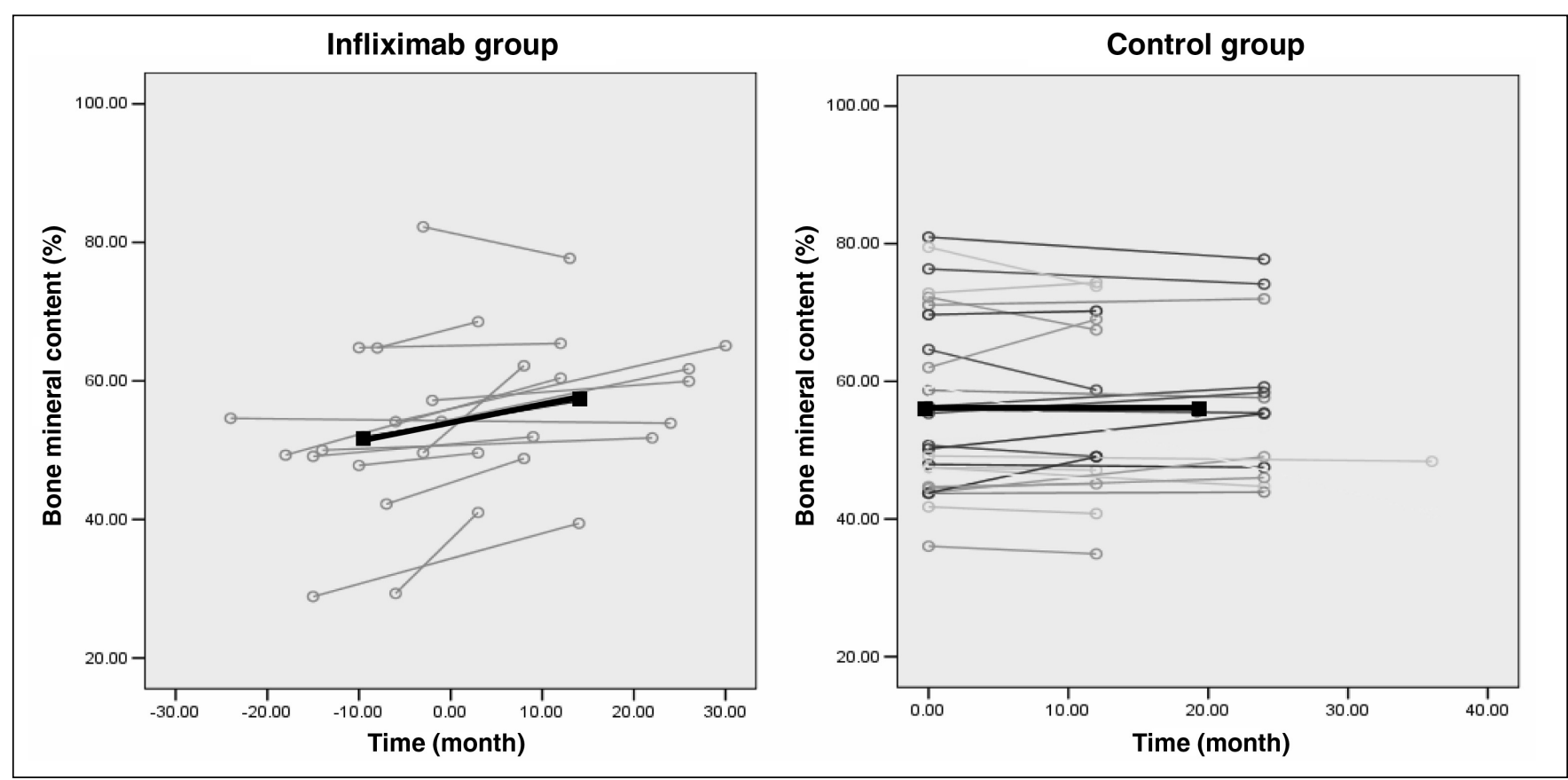

Figure 2) Changes in bone mineral content between both densitometric evaluations in the infliximab and control groups for each patient (grey lines with circles) and group means (black lines with squares). For the infliximab group, Time 0.00 indicates the time when infliximab therapy began

in the first or second lumbar BMD measurements, and $\mathrm{T}$ and $\mathrm{Z}$ scores between both groups. The subgroup had a significantly smaller increase in the lumbar BMC $(2.25 \% \pm 7.2 \%)$ than the infliximab group $(12.8 \% \pm 13.6 \%)(\mathrm{P}<0.01)$ (Figure 1$)$.

\section{DISCUSSION}

The present study showed that treatment with infliximab was associated with significant increases in lumbar bone area, $\mathrm{BMC}$ and $\mathrm{BMD}$ in patients with $\mathrm{CD}$. This improvement was significantly higher than the lumbar changes in patients with $\mathrm{CD}$ who never received treatment with infliximab.

Previous studies examining the effects of infliximab therapy on markers of bone turnover in patients with $\mathrm{CD}$ found a significant increase in markers of bone formation and a decrease in markers of bone resorption, which supported the theory that active, ongoing inflammation and high levels of circulating cytokines play a role in the pathogenesis of bone loss in patients with CD (26-28).

Bernstein et al (29) also found that maintenance treatment with infliximab improved BMD after one year in the lumbar spine $(2.4 \%$ increase $)$ and hip (2.6\% increase) in patients with $C D$, and that this effect was independent of concurrent administration of glucocorticoids. This study did not have a control group to compare differences in the changes in BMD.

Although we recognize that a randomized, controlled trial would be ideal, we believe that it would be very difficult to perform, because it would be unethical to assign a patient who has an indication to receive infliximab treatment to a control group. Thus, in our study, the infliximab group and the control group might have differed with respect to disease activity (ie, the control group might have had a milder form of the disease).

Osteopenia and osteoporosis are traditionally defined by BMD parameters, but this approach disregards the influence of bone size. Bone size, a main determinant of bone strength, plays a negative role in the BMD calculations $(\mathrm{BMD}=\mathrm{BMC} /$ area $)$. Therefore, we consider that $\mathrm{BMC}$ is the preferred variable when interpreting bone strength.

The CD patients who were treated with infliximab had an increase of nearly $14 \%$ in 22 months in their lumbar BMC. We found a strong correlation between final body weight and BMC in both groups, which suggested that nutritional status had an important influence on bone mass. In previous studies $(30,31)$, we have shown a strong correlation between lean mass (a measure of muscle mass) and BMC in the whole body and in different regions, suggesting that muscular mass and activity are important determinants of bone strength in CD. Between both densitometric evaluations, the control group had an improvement in their nutritional status, as shown by the nearly $7 \%$ increase in their body weight. This increase in body weight was significant compared with the infliximab group. Although the improvements in general well-being, nutritional status and physical activity were likely to play a role, the significant increases in lumbar bone area, $\mathrm{BMC}$ and BMD in the infliximab group, which were not associated with an increase in body weight, suggested that therapy of anti-TNF $\alpha$ might have had a favourable effect on bone metabolism by suppressing inflammatory cytokines, as has been shown in several in vitro studies (20-23).

Although treatment with glucocorticoids has been associated with deleterious effects on bone metabolism (32), results of cross-sectional and longitudinal studies in patients with $\mathrm{CD}$ have been conflicting. Several authors $(33,34)$ have found a negative correlation between glucocorticoid use and BMD, but others $(35,36)$ have found no influence of glucocorticoids on BMD. There is controversy as to whether this increased risk is due to the role of active inflammation in glucocorticoid users or due to glucocorticoids per se (37). In the present study, the subgroup of patients in the control group who received treatment 
with glucocorticoids between the densitometric evaluations demonstrated a small increase in lumbar BMC that could be associated with an improvement in their nutritional status and general well-being considering that they had a $10 \%$ increase in their body weight. The infliximab group demonstrated a significantly higher increase in lumbar BMC, and this increase was independent of concurrent administration of glucocorticoids.

The subgroup of patients in the control group who had flares or signs of disease activity between both densitometric determinations had a nearly $7 \%$ increase in their body weight, and they also demonstrated a $2 \%$ increase in their lumbar BMC that could be attributed to the improvements in their nutritional status and general well-being between the first and second evaluations. When the infliximab group was compared with the subgroup of patients in the control group who had flares or signs of disease activity between both densitometric determinations, there were significantly higher increases in the lumbar BMC and BMD in the infliximab group, despite the

\section{REFERENCES}

1. Bjarnason I, Macpherson A, Mackintosh C, Buxton-Thomas M, Forgacs I, Moniz C. Reduced bone density in patients with inflammatory bowel disease. Gut 1997;40:228-33.

2. Pollak RD, Karmeli F, Eliakim R, Ackerman Z, Tabb K, Rachmilewitz D. Femoral neck osteopenia in patients with inflammatory bowel disease. Am J Gastroenterol 1998;93:1483-90.

3. Schulte C, Dignass AU, Mann K, Goebell H. Reduced bone mineral density and unbalanced bone metabolism in patients with inflammatory bowel disease. Inflamm Bowel Dis 1998;4:268-75.

4. Martin JP, Tongue KA, Bhonsle U, Jacyna MR, Levi J. Bone mineral density in patients with inflammatory bowel disease. Eur J Gastroenterol Hepatol 1999;11:537-41.

5. Jahnsen J, Falch JA, Aadland E, Mowinckel P. Bone mineral density is reduced in patients with Crohn's disease but not in patients with ulcerative colitis: A population based study. Gut 1997;40:313-19.

6. Bernstein CN, Blanchard JF, Leslie W, Wadja A, Yu BN. The incidence of fracture among patients with inflammatory bowel disease. A population-based cohort study. Ann Intern Med 2000;133:795-9.

7. Vestergaard P, Krogh K, Rejnmark L, Laurberg S, Mosekilde L. Fracture risk is increased in Crohn's disease, but not in ulcerative colitis. Gut 2000;46:176-81.

8. Vestergaard P, Mosekilde L. Fracture risk in patients with celiac disease, Crohn's disease and ulcerative colitis: A nationwide follow-up study of 16,416 patients in Denmark. Am J Epidemiol 2002;156:1-10.

9. Siffledeen JS, Fedorak R, Siminoski K, et al. Bones and Crohn's: Risk factors associated with low bone mineral density in patients with Crohn's disease. Inflamm Bowel Dis 2004;10:220-8.

10. Habtezion A, Silverberg MS, Parkes R, Mikolainis S, Steinhart AH. Risk factors for low bone density in Crohn's disease. Inflamm Bowel Dis 2002;8:87-92.

11. Bernstein CN, Blanchard JF, Metge C, Yogendron M. The association between corticosteroid use and development of fractures among IBD patients in a population-based database. Am J Gastroenterol 2003;98:1797-801.

12. Card T, West J, Hubbard R, Logan RF. Hip fractures in patients with inflammatory bowel disease and their relationship to corticosteroid use: A population based cohort study. Gut 2004;53:251-5.

13. Andreassen H, Hylande E, Rix M. Gender, age and body weight are the major predictive factors for bone mineral density in Crohn's disease: A case-control cross-sectional study of 113 patients. Am J Gastroenterol 1999;94:824-8. fact that the patients in the control group who had flares or signs of disease activity had a significantly higher increase in body weight. This finding further suggests that anti-TNFa has a beneficial effect by suppressing the effect of inflammatory cytokines on bone metabolism.

Patients treated with bisphosphonates had an increase in their lumbar BMD that was not significantly different from that in patients who had not received treatment with bisphosphonates, both in the infliximab and control groups (data not shown). The number of patients treated with bisphosphonates was too low, and the study was not, therefore, powered to permit any conclusion to be drawn regarding the effect of bisphosphonates.

We conclude that infliximab therapy improved lumbar bone mass, and that this effect was independent of nutritional status improvement and concurrent administration of glucocorticoids. The mechanism of action of infliximab on bone metabolism and its long-term effects on fracture risks remain to be determined.
14. Sylvester FA, Wyzga N, Hyams JS, Gronowicz GA. Effect of Crohn's disease on bone metabolism in vitro: A role for interleukin-6. J Bone Miner Res 2002;17:695-702.

15. Murch SH, Lamkin VA, Savage MO, Walker-Smith JA, MacDonald TT. Serum concentrations of tumour necrosis factor alpha in childhood chronic inflammatory bowel disease. Gut 1991;32:913-7.

16. Komatsu M, Kobayashi D, Saito K, et al. Tumor necrosis factoralpha in serum of patients with inflammatory bowel disease as measured by highly sensitive immuno-PCR. Clin Chem 2001;47:1297-301

17. Lanfranchi GA, Tragnone A. Serum and faecal tumor necrosis factor-alpha as marker of intestinal inflammation. Lancet 1992;339:1053.

18. Udagawa N, Kotake S, Kamatani N, Takahashi N, Suda T. The molecular mechanism of osteoclastogenesis in rheumatoid arthritis. Arthritis Res 2002;4:281-9.

19. Oelzner P, Franke S, Muller A, Hein G, Stein G. Relationship between soluble markers of inmune activation and bone turnover in postmenopausal woman with rheumatoid arthritis. Rheumatology (Oxford) 1999;38:841-7.

20. Zhang YH, Heulsmann A, Tondravi MM, Mukherjee A, Abu-Amer Y. Tumor necrosis factor-alpha (TNF) stimulates RANKLinduced osteoclastogenesis via coupling of TNF type 1 receptor and RANK signaling pathways. J Biol Chem 2001;276:563-8.

21. Lam J, Takeshita S, Barker JE, Kanagawa O, Ross FP, Teitelbaum SL. TNF-alpha induces osteoclastogenesis by direct stimulation of macrophages exposed to permissive levels of RANK ligand. J Clin Invest 2000;106:1481-8.

22. Fuller K, Murphy C, Kirstein B, Fox SW, Chambers TJ. TNF-alpha potentially activates osteoclasts, through a direct action independent of any strongly synergistic with RANKL. Endocrinology 2002;143:1108-18.

23. Gilbert L, He X, Farmer P, et al. Inhibition of osteoblast differentiation by tumor necrosis factor-alpha. Endocrinology 2000;141:3956-64.

24. Hanauer SB, Feagan BG, Lichtenstein GR, et al. Maintenance infliximab for Crohn's disease: The ACCENT I randomized trial. Lancet 2002;359:1541-9.

25. Sands BE, Anderson FH, Bernstein CN, et al. Infliximab maintenance therapy for fistulizing Crohn's disease. N Engl J Med 2004;350:876-85.

26. Franchimont N, Putzeys V, Collette J, et al. Rapid improvement of bone metabolism after infliximab treatment in Crohn's disease. Aliment Pharmacol Ther 2004;20:607-14. 
27. Ryan BM, Russel MG, Schurgers L, et al. Effect of antitumour necrosis factor-alpha therapy on bone turnover in patients with active Crohn's disease: A prospective study. Aliment Pharmacol Ther 2004;20:851-7.

28. Abreu MT, Geller JL, Vasiliauskas EA, et al. Treatment with infliximab is associated with increased markers of bone formation in patients with Crohn's disease. J Clin Gastroenterol 2006;40:55-63.

29. Bernstein M, Irwin S, Greenberg GR. Maintenance infliximab treatment is associated with improved bone mineral density in Crohn's disease. Am J Gastroenterol 2005;100:2031-5.

30. Mauro M, Armstrong D. Evaluation of densitometric bone-muscle relationships in Crohn's disease. Bone 2007;40:1610-4.

31. Mauro M, Armstrong D. Juvenile onset of Crohn's disease: A risk factor for reduced lumbar bone mass in premenopausal women. Bone 2007;40:1290-3.
32. Lukert BP, Raisz LG. Glucocorticoid-induced osteoporosis. Rheum Dis Clin North Am 1994;20:629-50.

33. Robinson RJ, al-Azzawi F, Iqbal SJ, et al. Osteoporosis and determinants of bone density in patients with Crohn's disease. Dig Dis Sci 1998;43:2500-6.

34. Silvennoinen JA, Karttunen TJ, Niemela SE, et al. A controlled study of bone mineral density in patients with inflammatory bowel disease. Gut 1995;37:71-6.

35. Pigot F, Roux C, Chaussade S, et al. Low bone mineral density in patients with inflammatory bowel disease. Dig Dis Sci 1992;37:1396-403.

36. Motley RJ, Crawley EO, Evans C, Rhodes J, Compston JE. Increased rate of spinal trabecular bone loss in patients with inflammatory bowel disease. Gut 1988;29:1332-6.

37. Bernstein CN, Leslie WD, LeBoff MS. AGA technical review on osteoporosis in gastrointestinal diseases. Gastroenterology 2003;124:795-841. 


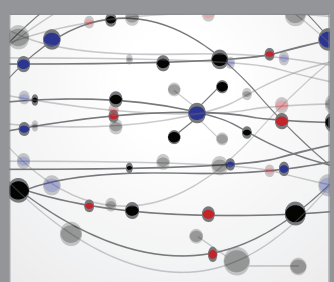

The Scientific World Journal
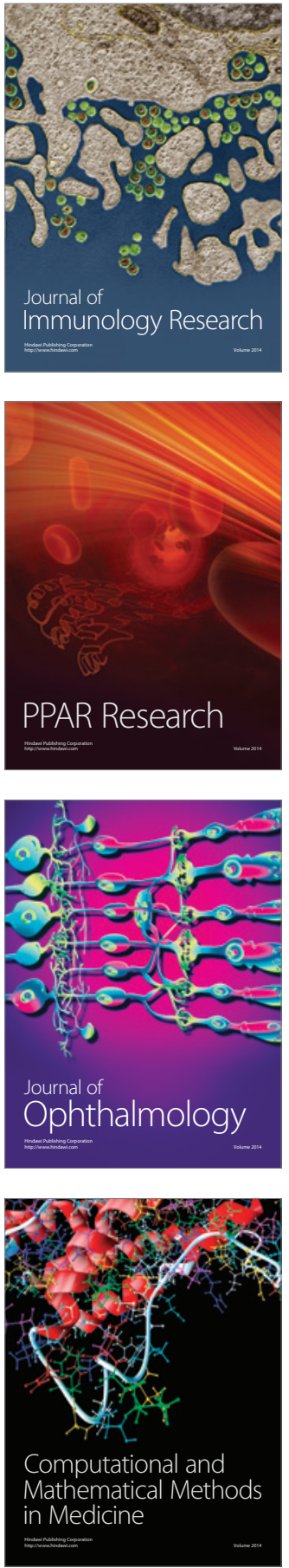

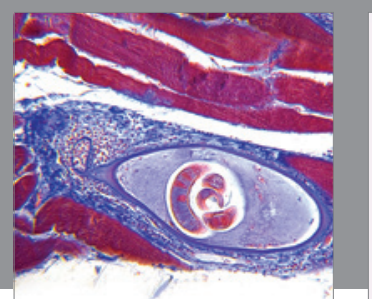

Gastroenterology Research and Practice

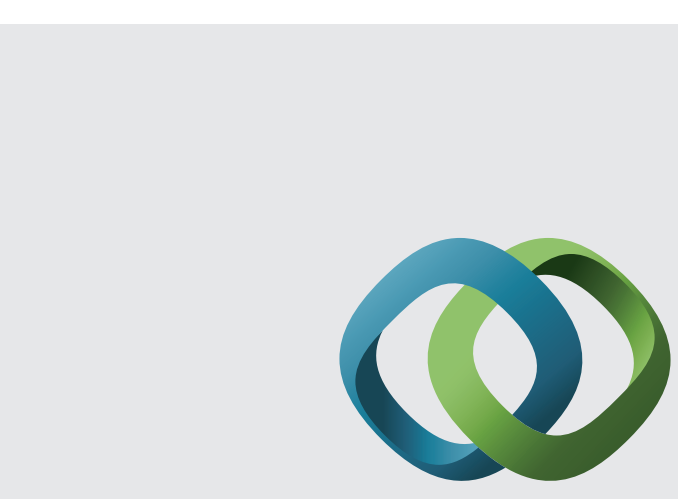

\section{Hindawi}

Submit your manuscripts at

http://www.hindawi.com
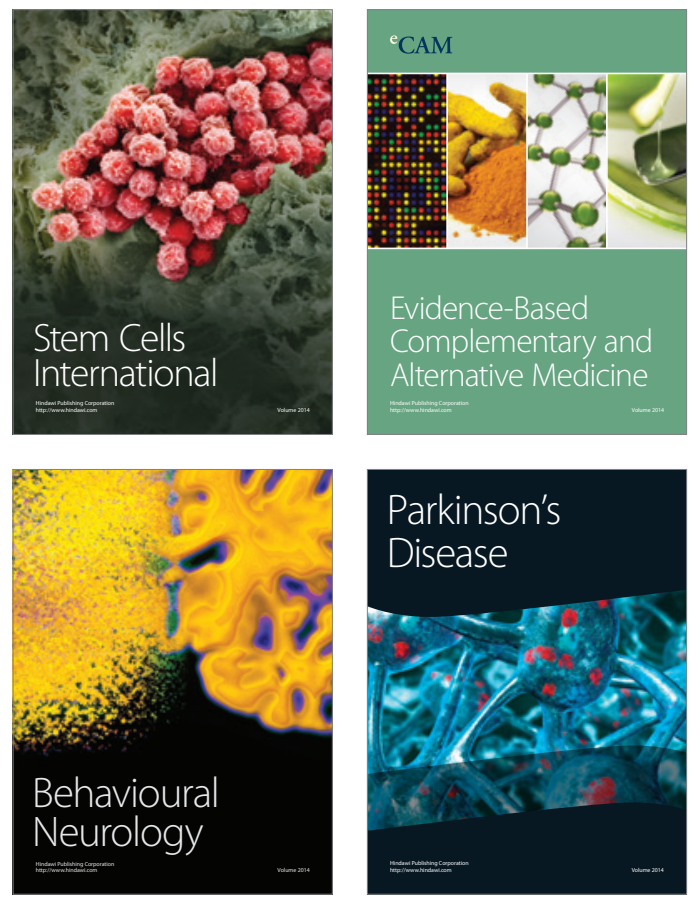
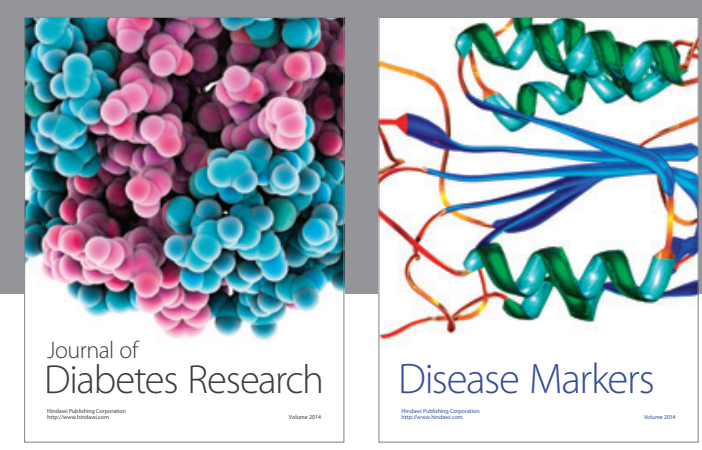

Disease Markers
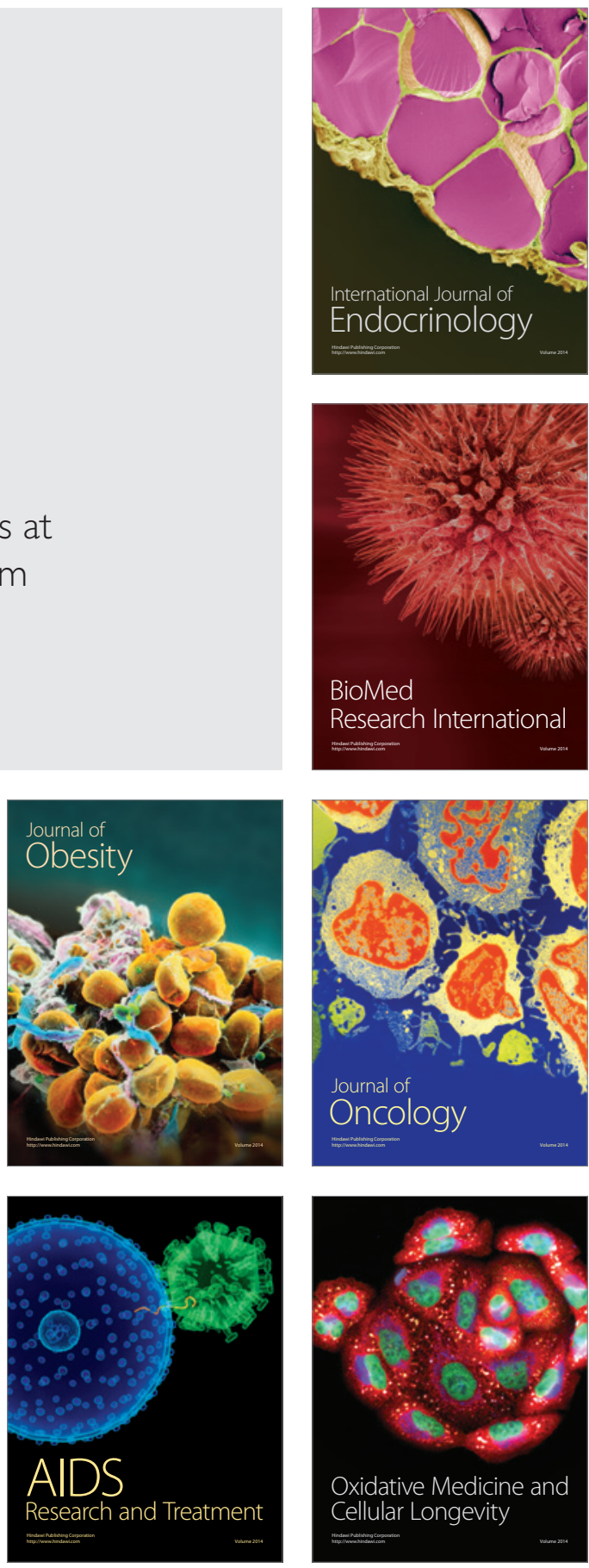